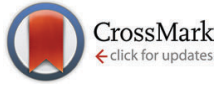

Cite this: J. Mater. Chem. B, 2015, 3, 7529

\title{
Inherently fluorescent and porous zirconia colloids: preparation, characterization and drug adsorption studies $\dagger$
}

\author{
L. Naszályi Nagy, ${ }^{\star a}$ J. Mihály, ${ }^{a}$ A. Polyak, ${ }^{b}$ B. Debreczeni, ${ }^{a}$ B. Császár, ${ }^{a c}$ \\ I. Cs. Szigyártó, ${ }^{a}$ A. Wacha, ${ }^{a}$ Zs. Czégény, ${ }^{a}$ E. Jakab, ${ }^{a}$ Sz. Klébert, ${ }^{a}$ E. Drotár, ${ }^{a}$ \\ G. Dabasi, ${ }^{d}$ A. Bóta, ${ }^{a}$ L. Balogh ${ }^{b}$ and É. Kiss ${ }^{c}$
}

\begin{abstract}
Porous, fluorescent zirconia particles of nearly $380 \mathrm{~nm}$ diameter were prepared without template molecules or labeling dyes. The porous structure is the result of aggregation-induced particle formation. The inherent fluorescence is assigned to coordinatively unsaturated $\mathrm{Zr}^{4+}$ ions at the sol-gel derived $\mathrm{ZrO}_{2}$ surface. After physico-chemical characterization of the native zirconia particles carboxyl and/or amine bearing drug molecules (D,L- $\alpha$-difluoromethylornithine - DFMO, ursolic acid - UA and doxorubicin - DOX) were adsorbed onto their surface, and the products were analyzed with Fourier-transform infrared spectroscopy (FTIR), thermogravimetry (TG), small-angle X-ray scattering (SAXS), fluorimetry and zeta potential vs. pH measurements. We have found that DOX complexes coordinatively unsaturated $\mathrm{Zr}^{4+}$ ions without dislocating them, while carboxyl-bearing drugs interact with basic surface $\mathrm{Zr}-\mathrm{OH}$ sites eliminating some of the carbonate species. The adsorption of UA at the zirconia surface shifts considerably the isoelectric point of the surface and thus provides kinetic stability to the particles at physiological $\mathrm{pH}$. An in vivo biodistribution study in two healthy dogs performed by SPECT/CT detection after ${ }^{99 \mathrm{~m}} \mathrm{Tc}$ labeling of the nanocarriers has shown the possibility of drug delivery application.
\end{abstract}

Received 5th May 2015

Accepted 21st August 2015

DOI: $10.1039 / c 5 t b 00832 h$

www.rsc.org/MaterialsB

\section{Introduction}

Nano- and microparticles of various kinds are currently investigated with the prospect of drug delivery application. The requirements to be fulfilled are numerous: drug carrier particles should encapsulate, transport and release drug molecules in a controlled way in living organism. ${ }^{1}$ Multifunctionality is, therefore, inevitable and - when coupled to easy synthesis represents a great advantage. Among inorganic particles silica $^{2,3}$ is preferred for its controlled synthesis, low toxicity, established conjugation methods and high drug loading capacity (for mesoporous silica).

\footnotetext{
${ }^{a}$ Institute of Materials and Environmental Chemistry, Research Centre for Natural Sciences, Hungarian Academy of Sciences (IMEC RCNS HAS), H-1117 Magyar Tudósok Blvd 2, Budapest, Hungary. E-mail: nagy.naszalyi.livia@ttk.mta.hu; Tel: $+36-1-382-6832$

${ }^{b}$ Department of Radiobiology, National Research Institute for Radiobiology and Radiohygiene (NRIRR), H-1221 Anna Str 5, Budapest, Hungary

${ }^{c}$ Department of Colloid Science, Loránd Eötvös University, H-1117 Pázmány Péter sétány 1/A, Budapest, Hungary

${ }^{d}$ Department of Nuclear Medicine, Semmelweis University, $H-1082$ Üllö Rd 78, Budapest, Hungary

$\dagger$ Electronic supplementary information (ESI) available: X-ray diffraction patterns, small-angle X-ray scattering curves and evaluated parameters, additional FT-infrared spectra and size distribution functions. See DOI: 10.1039/c5tb00832h
}

Zirconia, a ceramic material, is used for biomedical applications e.g. in dental and chirurgical implants. ${ }^{4-6}$ It is known to be biocompatible, and we have shown in our preliminary experiments that zirconia is also biodegradable under certain circumstances. The surface of zirconia is chemically active, having both acidic and basic sites. ${ }^{7}$ This explains that zirconia chemisorbs both $\mathrm{NH}_{3}$ and $\mathrm{CO}_{2}{ }^{8}$ Under ambient conditions, the zirconia surface is always covered by $\mathrm{CO}$ and $\mathrm{CO}_{2}$ adsorbed from the air. ${ }^{9,10}$ Complex formation has also been observed with the carboxyl groups of citric acid and poly-8-caprolactone. ${ }^{11,12}$ As was observed by Pokrovski et al. $\mathrm{CO}_{2}$ adsorption on monoclinic (m-) $\mathrm{ZrO}_{2}$ is more than an order of magnitude higher than that on tetragonal (t-) $\mathrm{ZrO}_{2}{ }^{13}$ High-temperature synthesis or annealing of $\mathrm{ZrO}_{2}$ leads to the transformation of the monoclinic phase into tetragonal.

However, the lack of a generally approved synthetic method providing stable $\mathrm{m}-\mathrm{ZrO}_{2}$ colloid hinders its use as a drug carrier. Nanocrystalline powders of $\mathrm{t}-\mathrm{ZrO}_{2}$ are produced by aqueous phase reaction followed by annealing. ${ }^{14-17}$ These materials sintered by a final annealing cannot be suspended to yield a stable uniform colloid. Spherical $\mathrm{m}-\mathrm{ZrO}_{2}$ are obtained from alkoxide precursors in alcohol after controlled hydrolysis and condensation. ${ }^{18-20}$ The diameter of these particles is usually over micrometer, and could only be reduced down to 
$200 \mathrm{~nm}$ by the addition of monovalent metallic cations. ${ }^{20}$ For a nano-sized object, the use of a template is necessary, ${ }^{21,22}$ however, this involves multi-step preparation.

In this paper we investigated the possibility of obtaining multifunctional: porous and fluorescent zirconia particles in one single synthetic step that are able to adsorb significant quantity of drug.

We intended to induce both porosity and fluorescence in $\mathrm{ZrO}_{2}$ starting from the method of Widoniak et al. ${ }^{20}$ where these functionalities were not described. Zhang and coworkers described cetyl trimethylammonium bromide (CTAB) induced fluorescence in $\mathrm{ZrO}_{2}$ powders. ${ }^{23}$ Zelcer et al. have produced mesoporous $\mathrm{ZrO}_{2}$ thin films with ordered porosity using Pluronics, Brij58 or CTAB as a template. ${ }^{24}$ The surfactant was eliminated in both procedures by annealing that we wished to avoid. We carried out preliminary experiments with CTAB templating as well, and tried to eliminate the surfactant by excessive washing. The structure and fluorescence of the obtained materials are compared and discussed in this paper.

Finally, the affinity of the obtained zirconia particles for carboxyl and/or amine bearing drug molecules was studied. For this study, three anticancer drug molecules were chosen: D,L- $\alpha$-difluoromethylornithine (DFMO, also known as eflornithine), doxorubicin (DOX) and ursolic acid (UA). There is a significant difference between them in several aspects: structure, solubility, acidity (Table 1).

In short, DFMO is a highly water soluble, nontoxic small molecule, whose main disadvantage is its rapid clearance from the body, therefore its clinical use for cancer treatment was stopped. DOX is a cardiotoxic drug, whose nanoformulated products are proven to be more efficient and less harmful than its free form. ${ }^{30} \mathrm{UA}$ is a natural anticancer compound, ${ }^{31,32}$ whose very low water solubility prevents its use in pharmaceutics. ${ }^{27}$

The structure of drug loaded $\mathrm{ZrO}_{2}$ particles was examined with SAXS in the present work. The affinity of DFMO, DOX and UA for the zirconia surface was investigated using TG, zeta potential-pH curves, and FTIR spectroscopy. The changes induced by drug adsorption in the porous and fluorescent properties of zirconia particles were also examined. Additionally, as ursolic acid loaded particles proved to be stable in physiological medium, they were radiolabelled with a technetium-99m $\left({ }^{99 \mathrm{~m}} \mathrm{Tc}\right)$ isotope. As labelling stability was excellent, normal biodistribution studies were performed in two healthy Beagle dogs using SPECT/CT imaging in order to prove in vivo particle size stability of NPs and verify the ability of the method to carry out prospective in vivo follow-up investigations of the drug delivery process.

Table 1 Properties of chosen drug molecules

\begin{tabular}{|c|c|c|c|c|}
\hline Drug & $\begin{array}{l}\text { Solubility in } \\
\text { water }\left(\mathrm{g}^{-1}\right)\end{array}$ & $\log P$ & $\begin{array}{l}\mathrm{p} K_{\mathrm{a}} \\
\text { strongest } \\
\text { acidic }\end{array}$ & $\begin{array}{l}\mathrm{p} K_{\mathrm{a}} \\
\text { strongest } \\
\text { basic }\end{array}$ \\
\hline $\begin{array}{l}\mathrm{DFMO}^{25} \mathrm{D}, \mathrm{L}-\alpha \text {-difluoro- } \\
\text { methylornithine, alias } \\
\text { eflornithine }\end{array}$ & 50.0 & -2 & 2.19 & 10.2 \\
\hline $\begin{array}{l}\text { DOX }^{26} \text { doxorubicin } \\
\text { UA ursolic acid }\end{array}$ & $\begin{array}{l}1.18 \\
0.076^{27}\end{array}$ & $\begin{array}{l}1.41 \\
6.43^{28}\end{array}$ & $\begin{array}{l}9.53 \\
5.29^{29}\end{array}$ & 8.94 \\
\hline
\end{tabular}

\section{Experimental section}

\section{Materials}

Absolute ethanol (a.r., $>99.7 \%,<0.2 \%$ water, Reanal), cesium chloride (CsCl, Specpure, trace metal basis), and zirconium(Iv) butoxide (TBOZ, $80 \mathrm{wt} \%$ in butanol, Sigma-Aldrich) were used for the optimized synthesis of $\mathrm{ZrO}_{2}$. TBOZ was kept and manipulated under argon gas. Cetyl trimethylammonium chloride (CTAB, $\geq 99 \%$, Acros Organics) was used in preliminary experiments for the induction of fluorescence and porosity. Ultrapure water was collected from a MilliQ System. D,L- $\alpha$-Difluoromethylornithine called also eflornithine (DFMO or E $\geq 97 \%$, Sigma), doxorubicin hydrochloride (DOX, 98.0\%, Calbiochem) and ursolic acid (UA, $\geq 90 \%$, Sigma-Aldrich) were used as received. Doxorubicin was kept in dark at $4{ }^{\circ} \mathrm{C}$. Methyl ethyl ketone (MEK, Reanal) was used for thin layer chromatography.

\section{Preparation of zirconia particles}

The synthesis route described by Widoniak et $a .^{20}$ was used with modifications. Briefly, a magnetic stirrer with oil bath, glassware, pipettes and reagents were put in a glove box. Freshly prepared $0.1 \mathrm{M} \mathrm{CsCl}$ solution was put in a screw cap vial. $100 \mathrm{ml}$ of abs. ethanol was poured into a $250 \mathrm{ml}$ glass vial, stirred at $300 \mathrm{rpm}$ with a triangle stir bar and heated to $60{ }^{\circ} \mathrm{C}$. The glove box was closed and flushed with argon. $0.4 \mathrm{ml} \mathrm{CsCl}$ solution was pipetted into the ethanol. After homogenization $3.25 \mathrm{ml}$ of TBOZ was quickly added to it and the glass vial was closed. The solution became white within one minute.

Next day the sol was centrifuged three times at $4000 \mathrm{rpm}$ (10 $\mathrm{min})$. The supernatant was discarded and the sediment was resuspended in ethanol by means of an ultrasonic homogenizer (150VT, BioLogics) (solid content: $8.3 \pm 0.8 \mathrm{mg} \mathrm{ml}^{-1}$; mean and standard deviation of 3 parallel measurements). The product was kept at $4{ }^{\circ} \mathrm{C}$.

\section{Drug adsorption}

$5 \times 10^{-6}$ mol DFMO (in powder), DOX (dissolved in $2.3 \mathrm{ml}$ water) and UA (dissolved in $3.8 \mathrm{ml}$ ethanol) were added to $5 \mathrm{ml}$ of $\mathrm{ZrO}_{2}$ sol $\left(64 \mathrm{mg} \mathrm{ZrO}_{2}\right.$ ). The mixtures were stirred (in dark for doxorubicin) for 3 days, and then they were centrifuged (4000 rpm, $18 \mathrm{~min}$ ). The sediment was rinsed with $3 \mathrm{ml}$ of water and centrifuged a second time. The particles were finally resuspended in $5 \mathrm{ml}$ water. Samples with adsorbed drug were labelled ZE (DFMO), ZD (doxorubicin) and ZU (ursolic acid).

The maximum drug encapsulation was determined adding $0.306 \mu \mathrm{mol}$ drug in $2 \mathrm{ml}$ ethanol to $300 \mu \mathrm{l}$ ethanolic sol $(2 \mathrm{mg}$ of $\mathrm{ZrO}_{2}$ ), stirring in dark for 3 days, centrifuging and analysing the supernatant.

\section{Characterization}

Structure and morphology of zirconia particles. Morphological investigation of the nanocarriers was carried out on a MORGAGNI 268(D) (FEI, Eindhoven, Netherlands) transmission electron microscope (TEM). The diluted $\mathrm{ZrO}_{2}$ sample was dropped and dried on carbon coated copper grids. 
Nitrogen physisorption measurements were performed at $77 \mathrm{~K}\left(196{ }^{\circ} \mathrm{C}\right)$ using a static volumetric apparatus (Quantachrome Autosorb 1C analyzer). The samples were previously degassed at $423 \mathrm{~K}\left(150{ }^{\circ} \mathrm{C}\right)$ for $30 \mathrm{~h}$. Nitrogen adsorption data were obtained using $c a .0 .1 \mathrm{~g}$ of the sample and successive doses of nitrogen until $p / p_{0}=1$ relative pressure was reached. Only the nitrogen adsorption volumes up to a relative pressure of 0.1 were considered in the micropore size distribution.

Powder X-ray diffraction was performed on a Philips PW 3710 diffractometer equipped with a PW 1050 Bragg Brentano goniometer, a graphite monochromator and a proportional counter. $\mathrm{Cu} \mathrm{K}_{\alpha}$ radiation was used as a source.

Small-angle X-ray scattering (SAXS) measurements were made on a laboratory-built CREDO (Creative Research Equipment for Diffraction) apparatus. ${ }^{33}$ X-rays were supplied by a $\mathrm{GeniX}^{3 \mathrm{D}} \mathrm{Cu}$ ULD integrated beam delivery system (Xenocs SA, Sassenage, France). The highly monochromatic $\mathrm{Cu} \mathrm{K}_{\alpha}$ radiation ( $0.15418 \mathrm{~nm}$ wavelength) was collimated by three pinholes of sizes 300, 300 and $400 \mu \mathrm{m}$ diameter. A small amount of dry powder from each sample was fixed between two layers of scotch tape and mounted onto the standard sample holder. SAXS patterns were recorded using a Pilatus-300k CMOS hybrid pixel two-dimensional position sensitive detector (Dectris Ltd, Baden, Switzerland) at two different sample-to-detector distances: 457 and $1218 \mathrm{~mm}$, in order to cover a wide range in the scattering variable ( $q=4 \pi \sin \theta / \lambda$ where $2 \theta$ is the scattering angle). The scattering patterns were corrected and calibrated using the on-line data reduction procedure implemented in the instrument control software. Subsequently, scattering patterns were azimuthally averaged, and the resulting one-dimensional scattering curves were scaled together in intensity and merged, yielding for each sample a single scattering curve covering the whole experimentally attainable angular range.

DLS measurements were carried out in a Malvern Zetasizer (NanoZS90, Malvern, Worcs, UK) equipped with a He-Ne laser $(\lambda=633 \mathrm{~nm})$ and a backscatter detector at a fixed angle of $173^{\circ}$. Input parameters were: refractive index of $\mathrm{ZrO}_{2}$ of 2.221, absorption coefficient of $\mathrm{ZrO}_{2}$ of 0.1, refractive index of ethanol of 1.359 , viscosity of 1.200 Pas, $20^{\circ} \mathrm{C}$. Twenty runs of 10 seconds each were recorded. The number weighted size distribution function was presented.

Drug adsorption studies. The $\mathrm{pH}$ dependent zeta potential values of the samples were recorded on the above Malvern apparatus at $20^{\circ} \mathrm{C} .0 .5 \mathrm{ml} \mathrm{ZrO}_{2}$, ZE, ZD and ZU suspensions in water were added $1 \mathrm{ml}$ of $0.01 \mathrm{M} \mathrm{NaCl}$ solution (final conc. $1 \mathrm{mM} \mathrm{NaCl}$ ), and the samples were diluted to $10 \mathrm{ml}$. The $\mathrm{pH}$ was set to 3 with $0.1 \mathrm{M} \mathrm{HCl}$ solution, and then $0.1 \mathrm{M} \mathrm{NaOH}$ solution was used to adjust $\mathrm{pH}$ values between 3 and 10 (JENWAY 3540 Bench Combined Conductivity/pH Meter). Each symbol on the $\zeta-\mathrm{pH}$ plot stands for the average and error of three measurements.

Drug adsorption at $\mathrm{ZrO}_{2}$ surface was demonstrated with attenuated total reflection infrared (ATR-FTIR) spectroscopy using a Varian Scimitar 2000 FTIR spectrometer (Varian Inc.) equipped with an MCT (mercury-cadmium-telluride) detector and a single reflection ATR unit ('Golden Gate', SPECAC Ltd, UK) with a diamond ATR element. Scans were performed in the wavenumber region $4000-500 \mathrm{~cm}^{-1}$. In general, $4 \mathrm{~cm}^{-1}$ resolution and records of 128 scans were applied.

Maximum drug loading was measured from the supernatant of drug loaded samples by UV-visible (DOX and DFMO) or ATR-FTIR (UA) spectroscopies. The picrylsulfonic acid colorimetric test was performed for the determination of eflornithine: to $500 \mu \mathrm{l}$ supernatant was added $500 \mu \mathrm{l} 0.1 \mathrm{M}$ borate buffer ( $\mathrm{pH} 9.28$ ) and $25 \mu \mathrm{l} 0.284 \mathrm{w} / \mathrm{v} \%$ picrylsulfonic acid solution in water.

Thermogravimetry (TG) provided information about the drug content of washed particles. TG measurements were performed on a modified Perkin-Elmer TGS-2 thermobalance. About $1 \mathrm{mg}$ sample dried previously at $90^{\circ} \mathrm{C}$ for $20 \mathrm{~h}$ was placed into the platinum sample pan and heated at $20^{\circ} \mathrm{C} \mathrm{min}{ }^{-1}$ up to $700{ }^{\circ} \mathrm{C}$ in a $21 \%$ oxygen containing argon atmosphere.

Fluorescence of $\mathrm{ZrO}_{2}, \mathrm{ZE}, \mathrm{ZD}$ and $\mathrm{ZU}$ samples was measured on a Shimadzu RF-5301PC spectrofluorimeter after 50-fold dilution of sols in water $\left(0.256 \mathrm{mg} \mathrm{ml}{ }^{-1} \mathrm{ZrO}_{2}\right.$ resulting solid content). Excitation and emission slit widths were $3 \mathrm{~nm}$. Spectra were recorded with $1 \mathrm{~nm}$ resolution. The excitation wavelength was $274 \mathrm{~nm}$.

Radiolabeling and normal distribution study. Radiolabeling examination was carried out on ZU particles $\left({ }^{99 \mathrm{~m}} \mathrm{Tc}-\mathrm{ZU}\right)$ via a previously applied method. ${ }^{34,35}$ Labeling efficiency of ${ }^{99 \mathrm{~m}} \mathrm{Tc}-\mathrm{ZU}$ particles was checked by thin layer chromatography using ITLC-SG plates (Agilent Technologies) with MEK eluent. In order to verify in vivo particle size stability and ${ }^{99 \mathrm{~m}} \mathrm{Tc}$-binding stability of the product, SPECT/CT imaging investigations were performed in a human SPECT/CT system (AnyScan, Mediso Ltd, $\mathrm{HU}$ ). Injected animals were two healthy Beagle dogs, the injected activity and volume of the product was $480 \mathrm{MBq}$ in $900 \mu$ l. After the intravenous (i.v.) application anaesthesia was induced, and $30 \mathrm{~min}$ later whole body SPECT/CT imaging was carried-out. Image fusion and quantitative analysis (thyroids, lungs, heart, liver, kidney and, urinary bladder uptakes) of ${ }^{99 \mathrm{~m}} \mathrm{Tc}-\mathrm{ZU}$ particles distribution was performed using region of interest analysis (ROI, Interview software, Mediso Ltd, HU).

Animals were kept and treated in compliance with all applicable sections of the Hungarian Laws No. XXVIII/1998 and LXVII/ 2002 on the protection and welfare of animals and animal welfare directions and regulations of the European Union.

\section{Results and discussion}

\section{Structure and morphology of zirconia particles}

The zirconia samples obtained in ethanol by controlled hydrolysis and condensation of zirconium(rv) butoxide possess a particle diameter over micrometer. ${ }^{19,20}$ The process is a multistep reaction as detailed by Widoniak et al. ${ }^{20}$ after hydrolysis of the metalorganic precursor small crystallites form, whose aggregation provides large secondary particles. The last reaction step is demonstrated by the whitening of the reaction mixture (usually within 1-5 min). According to our XRD and FTIR measurements, the small zirconia crystallites of $2.5 \mathrm{~nm}$ 


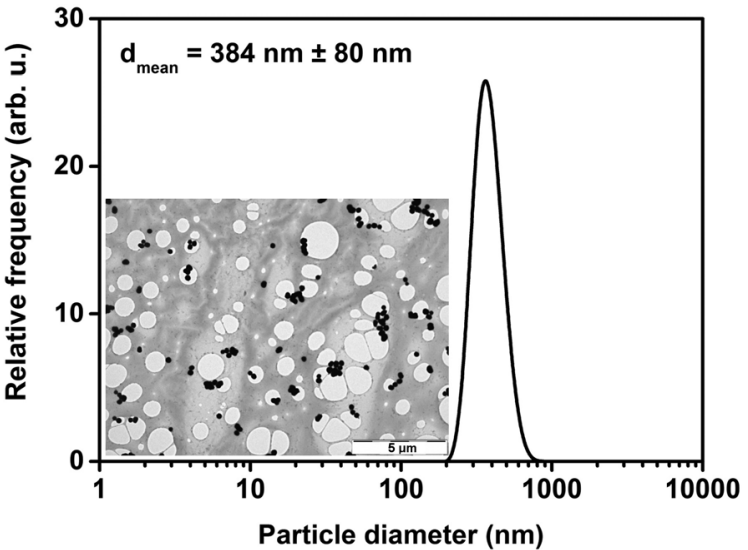

Fig. 1 TEM picture and DLS size distribution of $\mathrm{Cs}^{+}$-doped $\mathrm{ZrO}_{2}$ particles.

diameter are mainly crystallized in a monoclinic structure (see the diffractogram in Fig. S1 in the ESI $\dagger$ ).

The TEM analysis of $\mathrm{Cs}^{+}$-doped $\mathrm{ZrO}_{2}$ particles has evidenced particles with nearly 300-400 nm diameter (inset in Fig. 1). The mean hydrodynamic diameter evaluated from number weighted size distribution function is $384 \mathrm{~nm} \pm 80 \mathrm{~nm}$ (standard deviation) (Fig. 1). This $\mathrm{Cs}^{+}$-doped zirconia sol is thereafter called the Widoniak-type sol.

Induction of porosity in zirconia particles. During preliminary experiments we carried out CTAB templated syntheses in both ethanol and water to compare porous properties of the as-synthesized materials to that of Widoniak-type zirconia. In water, mesopores were obtained according to TEM observations, but a bulk material formed instead of spherical particles (Fig. S2(a) in the ESI $\dagger$ ).

Ethanol mediated sol gave rise to nearly $100 \mathrm{~nm}$ diameter particles (Fig. S2(b) in the ESI $\dagger$ ). However, when we examined the porous structure of templated and non-templated $\mathrm{ZrO}_{2}$, we observed the same pattern on SAXS curves (see Fig. S3(a) in the $\mathrm{ESI} \dagger$ ) corresponding to micropores. As the elimination of CTAB molecules by washing is time- and solvent-wasting, nontemplated (Widoniak-type, with $\mathrm{Cs}^{+}$ions) synthesis was further used for the synthesis of microporous zirconia. The effect of annealing $\left(400{ }^{\circ} \mathrm{C}, 5 \mathrm{~h}\right)$ has also been studied: the crystallite size of zirconia has increased to $65 \mathrm{~nm}$, and the prevailing crystal structure became tetragonal (see diffractograms in Fig. S4 in the ESI $\dagger$ ). The annealed samples were found to be aggregated and the SAXS curve did not show increased porosity (Fig. S3(b) in ESI $\dagger$ ). The elimination of template molecules by annealing is therefore unfavourable for drug carrier particle synthesis.

The scattering curve of the Widoniak-type zirconia powder sample shown in Fig. 2a starts with a power-law part, characteristic of the surface scattering of the aggregates of the primary $\mathrm{ZrO}_{2}$ particles. A least-squares fit to the starting part of the curve revealed the power-law exponent to be $-3.516 \pm 0.008$, which corresponds to 2.484 surface fractal dimension, reflecting that these larger entities are composed of the smaller, primary particles. ${ }^{36}$ The power-law part is followed by a knee in the scattering pattern, turning later on into another power-law. This section of the scattering curve is characteristic of the two-phase system formed by the primary particles and the pores between them, the curvature describing the average size, while the power-law carries information on the fractality. The corresponding parameters can be extracted from the curve by a least squares fit of an empirical, unified Guinier-Porod model to this range. ${ }^{37}$ According to this model we obtain $0.68 \pm$ $0.06 \mathrm{~nm}$ for the radius of gyration, which corresponds to $1.76 \mathrm{~nm} \pm$ $0.15 \mathrm{~nm}$ equivalent sphere diameter. The power-law exponent is $-2.75 \pm 0.03$, and since its magnitude is less than 3 , it corresponds to pore/mass fractal behaviour (instead of surface fractality), with a fractal exponent of $2.75 \pm 0.03$, describing the micropore structure. The fitting of the two parts of the scattering curves was done simultaneously, i.e. using the following function:

$$
I(q)=A q^{\alpha}+ \begin{cases}G \mathrm{e}^{-\frac{q^{2} R_{g}{ }^{2}}{3}} & \text { if } q<q^{*} \\ B q^{\beta} & \text { otherwise }\end{cases}
$$

b

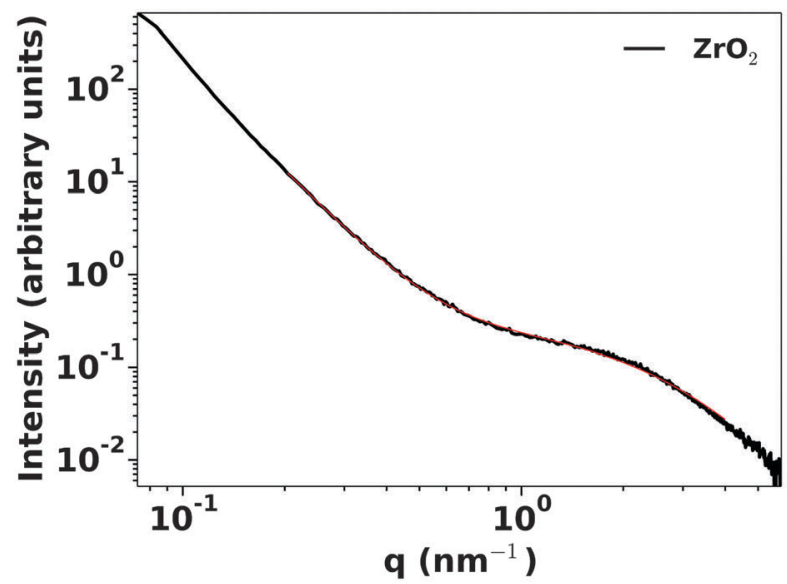

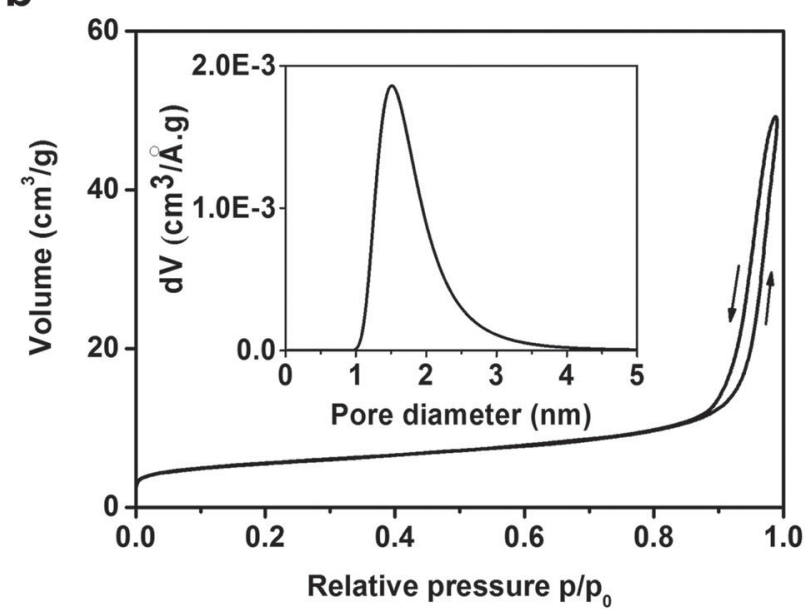

Fig. 2 (a) SAXS curve (thick black line) of the native $\mathrm{ZrO}_{2}$ sample and its least-squares fit (thin red line) with the model described in Experimental section and (b) nitrogen adsorption-desorption isotherm of $\mathrm{ZrO}_{2}$ powder and resulting pore size distribution function (inset). 
Here the first term corresponds to the starting power-law describing the surface scattering of the aggregates, and the second term is the unified Guinier-Porod model. In this model only the $G$ scaling factor, the $R_{\mathrm{g}}$ radius of gyration and the $\beta$ second power-law exponent are the free parameters, because $B$ and $q^{*}$ are determined from constraints of continuity in the function and its first derivative. The microporous structure of Widoniak-type zirconia was confirmed by $\mathrm{N}_{2}$ adsorption-desorption experiments (Fig. 2b). The BET surface area was $16 \mathrm{~m}^{2} \mathrm{~g}^{-1}$ (the value of $\mathrm{C}$ parameter was 466) and the total volume of micropores was $\sim 0.007 \mathrm{~cm}^{3} \mathrm{~g}^{-1}$, which are consistent with those found by Widoniak et $a l^{20}$ The maximum of pore size distribution is at $1.52 \mathrm{~nm}$, which is in very good agreement with the results found by SAXS. Interestingly, Widoniak et al. did not remark the microporous structure of the sample.

Induction of fluorescence in zirconia particles. Several studies have described rare earth doping-induced fluorescence in zirconia powders, ${ }^{38-43}$ but they dealt with di- and trivalent ions that prevent secondary particle formation in our case (experiments not shown). We therefore studied the method of Zhang et al. that describes fluorescence induced by CTAB residues after annealing. ${ }^{23}$ We annealed a portion of CTAB-templated zirconia, resuspended the powder in ethanol, and compared its fluorescence to that of a Widoniak-type sol (Fig. S5, ESI, $\dagger$ similar solid contents were applied). In additional experiments (not shown), the fluorescence of several metal-ion mediated synthesis products was recorded $\left(\mathrm{Pt}^{2+}, \mathrm{Pr}^{3+}, \mathrm{Ir}^{3+}\right)$, but band positions were always the same. We propose therefore that organic residues (or metal ion impurities) are not the origin of zirconia fluorescence as published by Zhang et al. ${ }^{23}$ this photoluminescence is an inherent characteristic of sol-gel derived zirconia particles, probably related to surface defects.

\section{Drug adsorption studies}

The fluorescent and microporous Widoniak-type zirconia was studied as a potential drug carrier particle. DFMO, DOX and UA were selected as carboxyl and/or amine bearing drug molecules
(DFMO carries both functionalities) and adsorbed at the particle surface (samples denoted as ZE, ZD and ZU).

The thermogravimetric analysis of dried samples permits us to separate the weight loss caused by desorption of water from that caused by the degradation of drug molecules (Fig. 3a).

The maximum of drug loading measured from supernatants and the drug content of washed particles are presented in Table 2. High and equal encapsulation efficiencies were observed from supernatants of the three drugs. Lower encapsulation efficiencies were obtained after washing, and the quantity of adsorbed drug increased oppositely to their solubility in water from DFMO to UA. The maximum DOX cargo of $\mathrm{ZrO}_{2}$ particles is close to the loading observed in the literature for mesoporous silica particles of similar size $(21 \mathrm{~m} / \mathrm{m} \%){ }^{44}$

The ATR-FTIR spectrum of native zirconia shows the presence of hydrogen carbonate $\left(\mathrm{HCO}^{3-}\right.$ at $1629,1464,1070$ and $\left.842 \mathrm{~cm}^{-1}\right)$ and of monodentate carbonate $\left(\mathrm{m}-\mathrm{CO}_{3}{ }^{2-}\right.$ at 1539, 1349, 1070 and $842 \mathrm{~cm}^{-1}$ ) species (Fig. 3b). These species are characteristic of the non-annealed monoclinic type zirconia surface. ${ }^{8,9,13}$ The presence of hydrogen carbonate on the zirconia surface was further supported by deuterium isotope change experiments: the antisymmetric stretching of $\left(\mathrm{HCO}^{3-}\right)\left(\right.$ at $\left.1629 \mathrm{~cm}^{-1}\right)$ disappeared and characteristic $\mathrm{D}_{2} \mathrm{O}$ vibrational bands appeared after two-day exposition of $\mathrm{ZrO}_{2}$ to $\mathrm{D}_{2} \mathrm{O}$ vapors (experiments not shown).

After drug loading, the quantity of adsorbed carbonate (both bicarbonate and monodentate carbonate) species has diminished. Characteristic IR bands of UA and DFMO become visible upon appropriate subtraction of the native zirconia spectrum from ZU and ZE spectra, respectively (Fig. S6 in the ESI $\dagger$ ). The subtraction is not possible in the case of DOX, because surface species have been transformed: the new bands at 1559,1381 and $1350 \mathrm{~cm}^{-1}$ are assigned to bridged carbonate (Fig. 3b). It is to note that the red doxorubicin solution turns immediately violet upon addition to zirconia suspension that suggests strong interactions between drug molecules and the inorganic surface (see UV-visible spectra in Fig. S7 in the ESI $\dagger$ ).
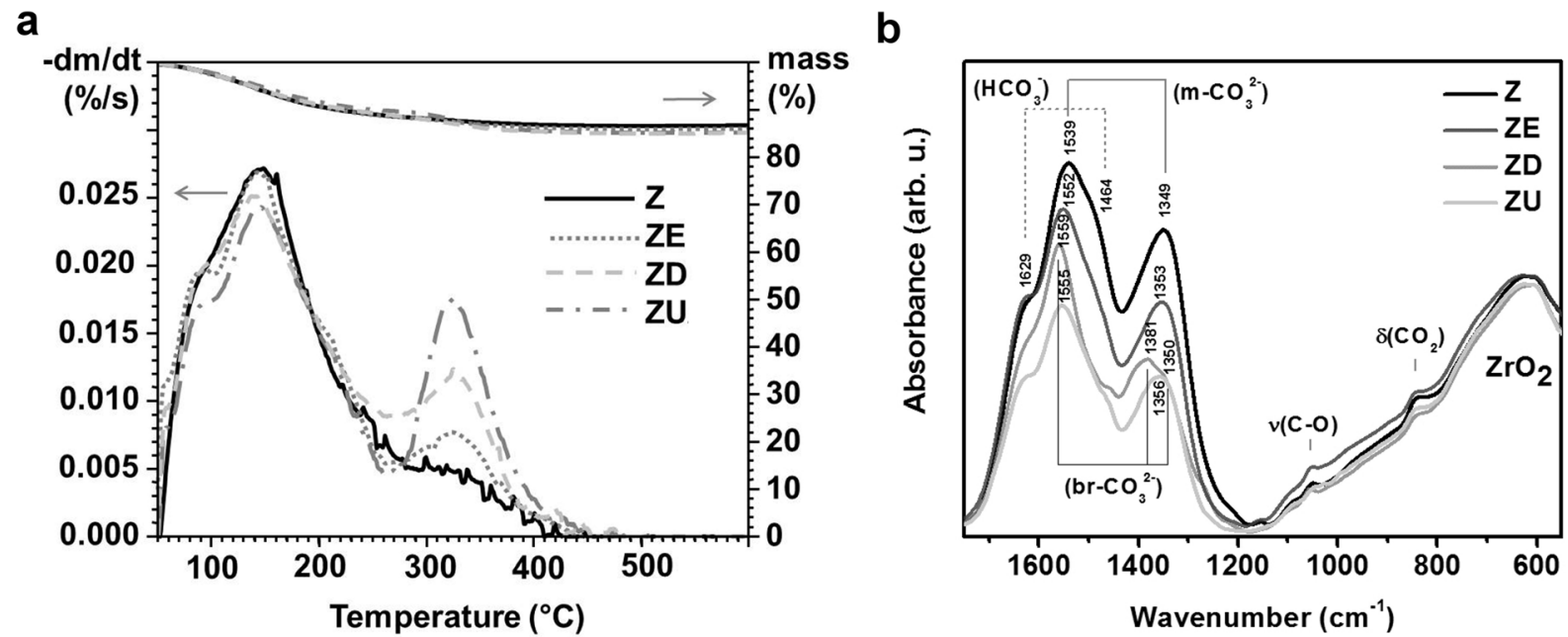

Fig. 3 (a) TG/DTA curves and (b) infrared spectra of the $\mathrm{ZrO}_{2}$ powders before and after drug adsorption. 
Table 2 Drug content and encapsulation efficiency

\begin{tabular}{lcc}
\hline & $\begin{array}{c}\text { Max. drug loading } \\
\text { (encapsulation efficiency } \mathrm{m} / \mathrm{m} \%)\end{array}$ & $\begin{array}{l}\text { Drug content }{ }^{b} \mathrm{~m} / \mathrm{m} \% \\
(\text { encapsulation efficiency } \mathrm{n} / \mathrm{n} \%)\end{array}$ \\
\hline DFMO & $4.8(87 \%)$ & $0.65(38 \%)$ \\
DOX & $14.5(88 \%)$ & $1.75(42 \%)$ \\
UA & $12.5(88 \%)$ & $2.60(61 \%)$ \\
& &
\end{tabular}

In effect, the complexation between doxorubicin's chinoidal oxygens and neighbouring phenol groups has previously been described with $\mathrm{Mn}^{2+}$ and $\mathrm{Cu}^{2+}$ ions. ${ }^{45,46}$ We did not find, however, any previous mention of the doxorubicin- $\mathrm{Zr}^{4+}$ complex.

We carried out supplementary experiments on the basis of Abraham's work. ${ }^{45} 100-200-300 \mathrm{mM} \mathrm{ZrOCl}_{2}$ solutions were made in $100 \mathrm{mM}$ HEPES buffer ( $\mathrm{pH}$ 8), and DOX solution was added to each one and to pure HEPES buffer $(86 \mu \mathrm{M}$ final DOX concentration). In the presence of $\mathrm{Zr}^{4+}$ ions, the solutions became immediately purple, the same as for native $\mathrm{ZrO}_{2}$ particles transferred into HEPES from ethanol by centrifugation. However, when native $\mathrm{ZrO}_{2}$ powder dried at $60{ }^{\circ} \mathrm{C}$ was resuspended in HEPES, DOX did not turn purple upon addition. In this case the carbonate species at the zirconia surface did not change, as revealed by FTIR spectroscopy (see FTIR spectra in Fig. S8 in the ESI $\dagger$ ). We assume that the surface area of zirconia is much reduced upon drying due to irreversible aggregation, and the number of surface defects providing complexation sites is also decreased in consequence.

The measurement of zeta potential as a function of $\mathrm{pH}$ is a sensitive method for the investigation of interactions at the surface of nanoparticles. The isoelectric point (IEP) of Widoniak-type zirconia is at $\mathrm{pH} 7.1$ (Fig. 4).

This corresponds to the value (7.0-7.3) reported earlier for pure zirconia. ${ }^{47}$ The IEP of the ZD sample coincides with that of pure zirconia. At first sight it seems that DOX does not establish a direct interaction with the zirconia surface. DFMO shifts slightly the IEP towards the acidic region ( $\mathrm{pH}$ 6.5). The largest shift corresponding to the highest affinity is observed for ursolic acid, where IEP becomes lower than $\mathrm{pH}$ 6. We also remarked that the surface charge at pH 7.5 (physiological) becomes lower

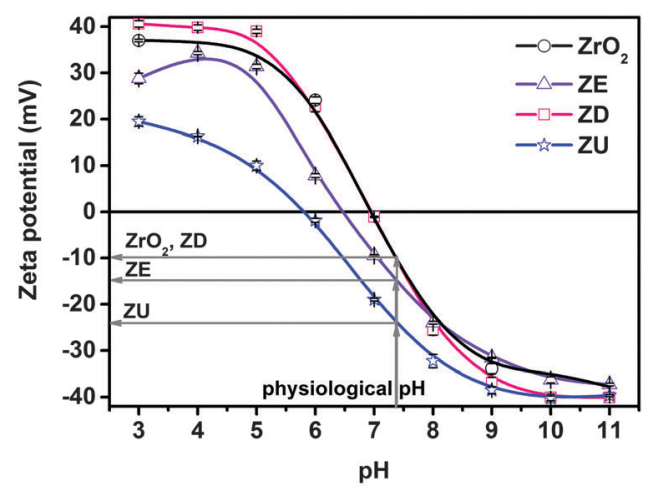

Fig. 4 Zeta potential vs. $\mathrm{pH}$ curves of the $\mathrm{ZrO}_{2}$ sol before and after drug adsorption.

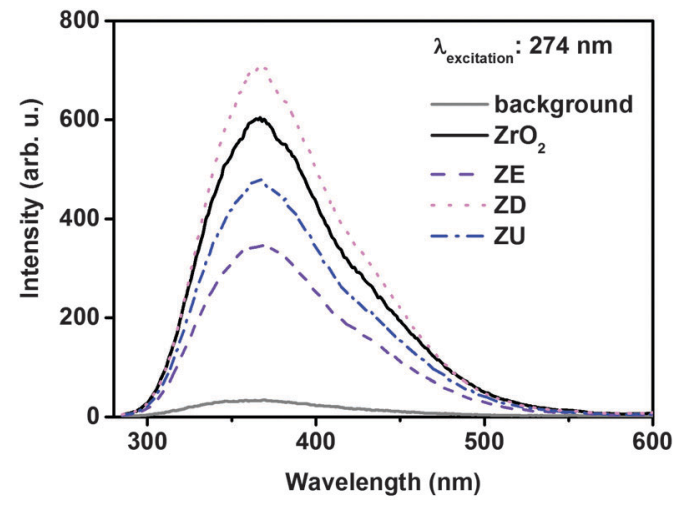

Fig. 5 Fluorescent emission curves of the $\mathrm{ZrO}_{2}$ sol before and after drug adsorption.

than $-20 \mathrm{mV}$ due to UA adsorption which may provide colloidal stability for the intended drug carrier at this $\mathrm{pH}$. These findings let us think that DFMO and UA adsorb directly at the metal oxide surface, while doxorubicin interacts in an indirect way.

We examined the changes induced by drug adsorption in luminescent properties of zirconia suspension (Fig. 5). Fluorescence emission bands are not shifted upon drug adsorption, but their intensity varies significantly (the solid content of samples was identical). In the presence of doxorubicin, the emission intensity increases, while for the two other drugs it decreases. These results indicate that the mechanism of fluorescence does not change upon drug adsorption. The quantum efficiency is higher when doxorubicin is present. DOX may inhibit non-radiative recombination or can play the role of a donor in the fluorescence resonance energy transfer (FRET) mechanism. However, the latter can be excluded since the excitation of zirconia is effectuated at much lower wavelength $(\sim 274 \mathrm{~nm})$ than the emission of doxorubicin $(\sim 600 \mathrm{~nm}) .{ }^{48}$ In the case of UA, the zirconia surface is supposed to transfer energy to the organic molecule, but the UV absorption of UA is below $200 \mathrm{~nm}$, therefore FRET quenching cannot take place. It seems that UA is simply lowering the number of active sites by adsorbing at active $\mathrm{Zr}^{4+}$ ions or eliminating carbonates interacting with active $\mathrm{Zr}^{4+}$ ions, while DOX is decreasing the probability of non-radiative recombination by complexing coordinatively unsaturated (cus) $\mathrm{Zr}^{4+}$ ions, or eventually by transforming surface carbonates into bridged carbonates. DFMO, on the other hand, is supposed to quench the fluorescence of zirconia through the FRET mechanism, since its highest wavelength UV absorption band is at $330 \mathrm{~nm}$.

Small-angle scattering curves of the loaded powder samples are presented in Fig. 6. They have similar features to those of the native zirconia sample, and the same mathematical models can be fitted. The results of the least-squares fitting in the case of all four samples (including the native one) are summarized in Table S1 (ESI $\dagger$ ). The first difference between the loaded and native samples is the relative weight of the scattering from the primary particle/micropore system, related to the starting powerlaw. This can be characterized numerically by the B/A ratio (according to the notation in the fitting function in Experimental section). 


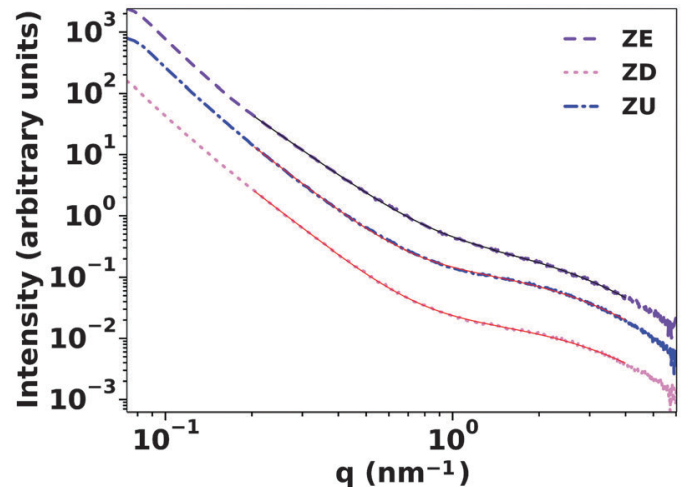

Fig. 6 SAXS curves (thick lines) of the loaded zirconia samples and the corresponding least-squares fits (thin lines).

As seen from the table, this ratio is significantly smaller for the loaded powders. This is expected, as the absolute scattering weight of the pore system decreases the electron density contrast between the pore and the $\mathrm{ZrO}_{2}$ phases decreases, and the scattering contribution of the aggregates does not change much. This is also expressed in the fact that the first powerlaw exponents do not change significantly, thus the aggregates retain their surface fractal properties.

The radii of gyration determined from the micropore part do decrease, however, only slightly. The most prominent change is found in the case of $\mathrm{ZD}$, where the original, approx. $0.68 \mathrm{~nm}$ radius of gyration decreased to 0.56 , corresponding to $1.44 \mathrm{~nm}$ equivalent sphere radius. This decrease in all of the loaded samples may also be attributed to the filling of the pores. It can be assumed that the filling substance forms thicker, denser layers near the pore walls and contained more loosely in the lumina of the pores.

Definition of surface structures. According to all our observations, we have constructed model structures for the interpretation of surface interactions of the three drug molecules studied (Fig. 7). Here we present the most probable structures, whose presence have either been spectrally proven or suggested on the basis of FTIR and UV-visible spectroscopy, fluorimetry, zeta potential results and previous observations. ${ }^{9,11,13,49}$ Doxorubicin is proposed to complex cus $\mathrm{Zr}^{4+}$ ions at the surface without dislocating them. The origin of luminescent properties may also be cus $\mathrm{Zr}^{4+}$ ions, but this hypothesis needs further investigation. Because of surface $\mathrm{Zr}^{4+}$ complexation, the carbonate structure is changed, and the bridged type of carbonate becomes dominant. The lack of change in the isoelectric point of $\mathrm{ZrO}_{2}$ might be the result of an equimolar consumption and formation of surface negative charges $\left(-\mathrm{O}^{-}\right)$. The amino groups of DOX may enter into electrostatic interactions with surface carbonate species, since these are in the ionic from according to FTIR shifts. DFMO and UA mainly replace surface carbonates by linking directly to basic sites, but are also supposed to be involved in H-bonds.

\section{Radiolabeling and normal distribution study}

As the zeta potential-pH measurement has shown that the ZU sample may be stable under physiological conditions an aliquot of ZU suspension was centrifuged and the particles were suspended in $10 \mathrm{mM}$ phosphate buffer ( $\mathrm{pH}$ 7.5). DLS measurements proved that these particles maintained their dispersity over a period of 10 days at room temperature (Fig. S9 in ESI $\dagger$ ). Samples were thereafter radiolabelled.

${ }^{99 \mathrm{~m}}$ Tc-radiolabeling proved to be a simple and rapid procedure. Labeling efficiency was above $98 \%$ and excellent in vitro ${ }^{99 \mathrm{~m}}$ Tc-binding stability could be observed.

The normal biodistribution of the ${ }^{99 \mathrm{~m}} \mathrm{Tc}-\mathrm{ZU}$ sample in two healthy beagle dogs is shown in Fig. 8. During the anaesthesia, i.v. applications and the SPECT/CT examinations clinical sideeffects were not recorded in the animals.

High liver ( $44 \%$ and $48 \%$ of total injected activity) and urinary bladder uptakes were seen 30 min post i.v. applications. Moderate accumulations were recorded in the kidneys and negligible by the thyroids, heart and lungs. The results indicated that the size of injected nanoparticles is strictly lower than $1000 \mathrm{~nm}$ (because of very low detectable accumulation in the lungs) while NPs have a stable ${ }^{99 \mathrm{~m}}$ Tc-binding capability (concluded from very low thyroid uptakes).

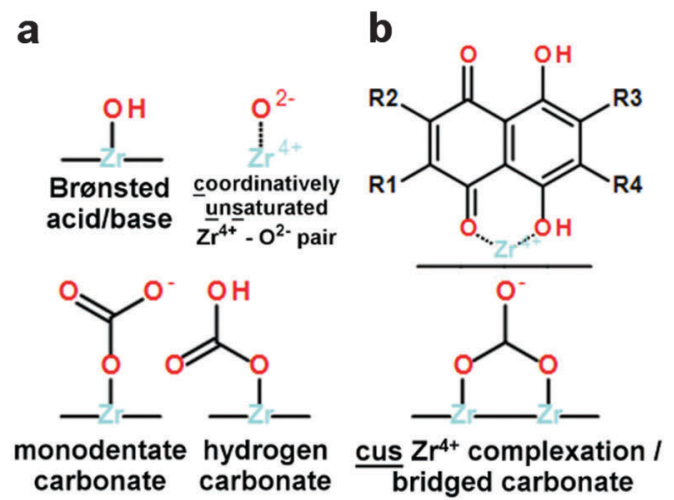

C

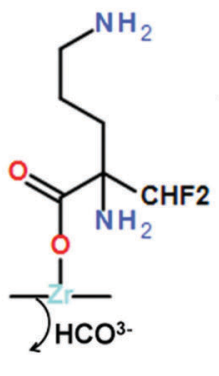

d

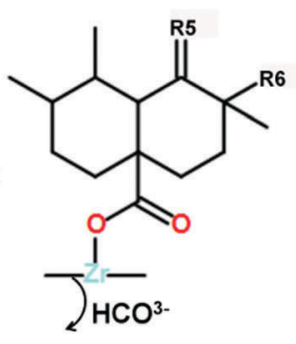

Fig. 7 Proposed surface structures for zirconia (a) before drug adsorption and after (b) doxorubicin, (c) DFMO and (d) ursolic acid adsorption onto the zirconia surface. Cus stands for "coordinatively unsaturated". 


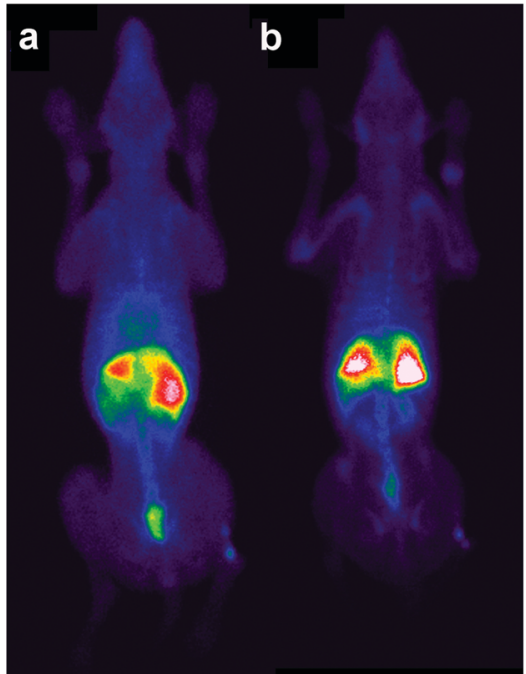

Fig. 8 Normal biodistribution examinations of ${ }^{99 m} \mathrm{Tc}$-labeled ursolic acid-capped zirconia ( ${ }^{99 \mathrm{~m}} \mathrm{Tc}$-ZU) nanoparticles. Whole body SPECT/CT scans of two healthy Beagle dogs ( $a$ and b) 30 minutes post i.v. application: high liver and urinary bladder uptakes.

\section{Conclusions}

In conclusion, we have revealed that the synthetic method elaborated by Widoniak et al. ${ }^{20}$ yielded inherently fluorescent and microporous zirconia particles that has not yet been remarked in the literature. We assume that the inherent fluorescence observed for colloidal $\mathrm{ZrO}_{2}$ particles originates from surface defects (possibly coordinatively unsaturated $\mathrm{Zr}^{4+}$ ions), whose number decreases upon aggregation, drying and annealing of the particles. Despite the great structural differences in their molecular structure, carboxyl-bearing DFMO and UA identically link to basic surface sites eliminating some of the surface carbonate species. We have evidenced that doxorubicin enters into strong complexation interaction with coordinatively unsaturated $\mathrm{Zr}^{4+}$ species without moving them away from the surface (increased fluorescence) similar to that observed for $\mathrm{Mn}^{2+}$ ions. ${ }^{45}$ This process perturbs, however, surface carbonate species and transforms them into bridged carbonate (band changes in FTIR spectra). The carrier particle retains its fluorescent properties upon drug adsorption, and ursolic acid even stabilizes the particles at physiological $\mathrm{pH}$. Preliminary radiolabeling and follow-up probes verified that the method is able to carry out prospective SPECT/CT drug delivery follow-up studies with the ${ }^{99 \mathrm{~m}}$ Tc-labelled ursolic acid-capped zirconia. The use of such zirconia particles seems to be particularly interesting in the future for topical radiotherapy with $\beta$-emitting isotopes that induce fast degradation in polymeric nanocarriers.

\section{Acknowledgements}

The authors gratefully acknowledge István Sajó for XRD measurements and evaluation, Péter Baranyai for fluorimetry evaluation, Prof. János Mink and Tibor Kremmer for their precious advices. The above experiments were supported by
Jedlik projects OM-00162/2007, 2007ALAP1-00070/2008 of the National Innovation Office (NIH, Hungary) and the grant agreement CNK-81056 of the Hungarian Scientific Research Fund (OTKA, Hungary). The financial support did not take a share in publishing.

\section{Notes and references}

1 V. Torchilin, Multifunctional Pharmaceutical Nanocarriers, Springer, Berlin, Heidelberg, 2008.

2 M. D. Popova, Á. Szegedi, I. N. Kolev, J. Mihály, B. S. Tzankov, G. T. Momekov, N. G. Lambov and K. Yoncheva, Int. J. Pharm., 2012, 436(1-2), 778-785.

3 M. Yu, S. Jambhrunkar, P. Thorn, J. Chen, W. Gu and C. Yu, Nanoscale, 2013, 5(1), 178-183.

4 M. Srinivas and G. Buvaneswari, Trends Biomaters. Artif. Organs., 2006, 20(1), 24-30.

5 M. Hisbergues, S. Vendeville and P. Vendeville, J. Biomed. Mater. Res., Part B, 2009, 88(2), 519-529.

6 R. J. Kohal, M. Bächle, W. Att, S. Chaar, B. Altmann, A. Renz and F. Butz, Dent. Mater., 2013, 29(7), 763-776.

7 E. M. Köck, M. Kogler, T. Bielz, B. Klötzer and S. Penner, J. Phys. Chem. C, 2013, 117(34), 17666-17673.

8 B. Bachiller-Baeza, I. Rodriguez-Ramos and A. GuerreroRuiz, Langmuir, 1998, 14(13), 3556-3564.

9 J. Mihály, J. Kristóf, J. Mink, L. Nanni, D. Patracchini and A. D. Battisti, Study of ZrO2 Coatings by Thermoanalytical and Fourier Spectroscopic Methods, in Progress in Fourier Transform Spectroscopy, ed. J. Mink, G. Keresztury and R. Kellner, Springer, Vienna, 1997, pp. 617-619.

10 M. Daturi, C. Binet, S. Bernal, J. A. P. Omil and J. C. Lavalley, J. Chem. Soc., Faraday Trans., 1998, 94(8), 1143-1147.

11 J. H. Choy and Y. S. Han, J. Mater. Chem., 1997, 7(9), 1815-1820.

12 M. Catauro, M. Raucci and G. Ausanio, J. Mater. Sci.: Mater. Med., 2008, 19(2), 531-540.

13 K. Pokrovski, K. T. Jung and A. T. Bell, Langmuir, 2001, 17(14), 4297-4303.

14 L. Zhou, J. Xu, X. Li and F. Wang, Mater. Chem. Phys., 2006, 97(1), 137-142.

15 Y. Jia, Y. Hotta, C. Duran, K. Sato and K. Watari, J. Ceram. Soc. Jpn., 2005, 113(5), 380-382.

16 M. Rashad and H. Baioumy, J. Mater. Process. Technol., 2008, 195(1-3), 178-185.

17 C. Suciu, A. Hoffmann and P. Kosinski, J. Mater. Process. Technol., 2008, 202(1-3), 316-320.

18 T. Ogihara, N. Mizutani and M. Kato, Ceram. Int., 1987, 13(1), 35-40.

19 T. Ogihara, N. Mizutani and M. Kato, J. Am. Ceram. Soc., 1989, 72(3), 421-426.

20 J. Widoniak, S. Eiden-Assmann and G. Maret, Eur. J. Inorg. Chem., 2005, 3149-3155.

21 S. Tang, X. Huang, X. Chen and N. Zheng, Adv. Funct. Mater., 2010, 20(15), 2442-2447.

22 J. M. Kim, S. M. Chang, S. Kim, K. S. Kim, J. Kim and W. S. Kim, Ceram. Int., 2009, 35(3), 1243-1247. 
23 C. Zhang, C. Li, J. Yang, Z. Cheng, Z. Hou, Y. Fan and J. Lin, Langmuir, 2009, 25(12), 7078-7083.

24 A. Zelcer and G. J. A. A. Soler-Illia, J. Mater. Chem. C, 2013, 1(7), 1359-1367.

25 J. De Oliveira Eloy, J. Saraiva, S. de Albuquerque and J. M. Marchetti, AAPS PharmSciTech, 2012, 13(4), 1436-1445.

26 Y. Zhang, K. Xue, E. Y. Zhao, Y. Li, L. Yao, X. Yang and X. Xie, Pharmacogn. Mag., 2013, 9(suppl 1), S19-S24.

27 H. Du and X. Q. Chen, J. Iran. Chem. Soc., 2009, 6(2), 334-340.

28 DrugBank, http://www.drugbank.ca/drugs/DB03856.

29 DrugBank, http://www.drugbank.ca/drugs/DB00997.

30 R. J. Hunter and V. R. Preedy, Nanomedicine is Health and Disease, CRC Press, 2011, p. 454.

31 H. J. Cha, M. T. Park, H. Y. Chung, N. D. Kim, H. Sato, M. Seiki and K. W. Kim, Oncogene, 1998, 16(6), 771-778.

32 H. Zhang, X. Li, J. Ding, H. Xu, X. Dai, Z. Hou, K. Zhang, K. Sun and W. Sun, Int. J. Pharm., 2013, 441(1-2), 261-268.

33 A. Wacha, Z. Varga and A. Bóta, J. Appl. Crystallogr., 2014, 47, 1749-1754.

34 A. Polyák, I. Hajdu, M. Bodnár, G. Trencsényi, Z. Pöstényi, V. Haász, G. Jánoki, G. A. Jánoki, L. Balogh and J. Borbély, Int. J. Pharm., 2013, 449(1-2), 10-17.

35 A. Polyák, L. Naszályi Nagy, A. Bóta, G. Dabasi, R. P. Jóba, G. Trencsényi, Z. Pöstényi, V. Haász, G. Jánoki and L. Balogh, EANM'14, Gothenburg, Sweden, 2014, vol. 42(2), S442.

36 P. W. Schmidt, J. Appl. Crystallogr., 1991, 24(5), 414-435.

37 B. Hammouda, J. Appl. Crystallogr., 2010, 43, 716-719.

38 M. R. N. Soares, C. Nico, M. Peres, N. Ferreira, A. J. S. Fernandes, T. Monteiro and F. M. Costa, J. Appl. Phys., 2011, 109(1), 013516.
39 F. Ramos-Brito, C. Alejo-Armenta, M. García-Hipólito, E. Camarillo, A. J. Hernández, S. H. Murrieta and C. Falcony, Opt. Mater., 2008, 30(12), 1840-1847.

40 S. E. Paje and J. Llopis, Appl. Phys. A: Mater. Sci. Process., 1993, 57(3), 225-228.

41 Z. Assefa, R. G. Haire and P. E. Raison, Spectrochim. Acta, Part A, 2004, 60(1-2), 89-95.

42 J. Azorín, T. Rivera, C. Furetta and A. Sánchez-Rodríguez, Mater. Sci. Forum, 2005, 480-481, 145-148.

43 A. Aytimur, I. Uslu, S. Koçyiğit and F. Özcan, Ceram. Int., 2012, 38(5), 3851-3856.

44 J. Shen, Q. He, Y. Gao, J. Shi and Y. Li, Nanoscale, 2011, 3, 4314-4322.

45 S. A. Abraham, K. Edwards, G. Karlsson, S. MacIntosh, L. D. Mayer, C. McKenzie and M. B. Bally, Biochim. Biophys. Acta, Biomembr., 2002, 1565(1), 41-54.

46 A. Kheirolomoom, L. M. Mahakian, C. Y. Lai, H. A. Lindfors, J. W. Seo, E. E. Paoli, K. D. Watson, E. M. Haynam, E. S. Ingham, L. Xing, R. H. Cheng, A. Borowsky, R. D. Cardiff and K. W. Ferrara, Mol. Pharmaceutics, 2010, 7(6), 1948-1958.

47 C. Renger, P. Kushel, A. Kristoffersson, B. Clauss, W. Oppermann and W. Sigmund, J. Ceram. Process Res., 2006, 7(2), 106-112.

48 X. Dai, Z. Yue, M. E. Eccleston, J. Swartling, N. K. H. Slater and C. F. Kaminski, Nanomedicine, 2008, 4(1), 49-56.

49 Z. Bacsik, N. Ahlsten, A. Ziadi, G. Zhao, A. E. Garcia-Bennett, B. Martín-Matute and N. Hedin, Langmuir, 2011, 27(17), 11118-11128. 